\title{
ROBÔ ACIONADO POR COMANDO DE VOZ
}

\author{
Gustavo Madeira da Silva - \\ Gustavo.madeira@alunos.unis.edu.br Marcos Basílio da Silva - \\ Marcos.basilio@alunos.unis.edu.br Matheus Basílio da Silva - \\ Matheus.basilio@alunos.unis.edu.br Rafael de Almeida \\ Oliveira - Rafael.oliveira2@alunos.unis.edu.br
}

\section{RESUMO}

Opresentetrabalhotem como escopo a a dofuncionamentoeconstruçãodeumrobôautônomomóvel,com a capacidade de interpretar comandos de voz e relacioná-los a ações, visando, de forma primordial, facilitar a realização de atividades humanas, isso é, a mão de obra humana, podendo-se citar a título de exemplo, trabalhos perigosos, bem como aqueles que expõem o ser humano à situações de risco. A navegação do robô autônomo e o reconhecimento dos comandos são realizadospor meio da utilização do Arduino UNO, sendo este um microcontrolador de placa única, com a finalidade de percorrer uma trajetória determinada pelocomando. Para tanto, a metodologia utilizada visou sustentar a construção de um robô comandado por meio de voz, almejando a sustentação, ou melhor, o embasamento para a construção de possíveis trabalhos futuros nesta área. Pode-se ressaltar que a técnica de pesquisa foi voltada para a leitura, em primeiro momento, exploratória, assim como, seletiva, em acervo bibliográfico, bem como documental e sítios pertinentes quanto ao assunto constante do recorte desta pesquisa.Por fim, analisa-se que os resultados alcançados com a construção do referido robô são satisfatórios, demonstrando êxito do método escolhido, ou melhor, utilizado. 
Palavra-Chave: robô,robô autônomo móvel,comandos de voz, Arduíno UNO

\section{INTRODUÇÃO}

Desdeosprimórdiosdesuaorigem,oserhumanosempreseutilizoudeferramentaseutensílios para auxiliar a realização de tarefas cotidianas relacionadas às suas necessidades de sobrevivência (Romano, V.; Dutra, M, 2002). Ao longo dos séculos, esse auxílio e facilitação foramobtidosemsuagrandemaioriacomautilização da tecnologia, sendo esta sinônimo de robótica, nas últimas décadas.

Um robô é definido, segundo a norma ISO (International Organization for Standardization) 10218, como "uma máquina manipuladora, com vários graus de liberdade, controlada automaticamente, reprogramável, multifuncional, que pode ter base fixa ou móvel para utilização em aplicações de automação industrial”.

$\mathrm{Na}$ área da robótica, é evidente o potencial de aplicações dos robôs autônomos móveis, em especial em tarefas perigosas, sujas ou desagradáveis. As aplicações propostas para robótica avançada abrangem grande parte da atividade humana, o que incluem: luta contra o fogo, salvamento de emergência, prevenção de desastres, patrulha de segurança, limpeza industriale doméstica, serviço doméstico, manipulação de pacientes, operações de procura em ambientes distantes e/ou inóspitos, etc. Uma caraterística comum destas aplicações é a exigência de um veículo móvel ou plataforma, que sirva como base para qualquer tarefa exigida. A exigência comum para tal veículo, é a habilidade para navegar de uma posição conhecida a uma nova localização (Jácobo, Justo Emilio Alvarez,2001).

Diante do exposto, é imprescindível salientar que o presente trabalho tem como objetivoadescriçãodoprojetoeimplementaçãodeumsistemarobóticocom a capacidade de interpretar comandos de voz, sendo capaz de se mover de uma posição conhecida a uma nova localização determinada pelocomando.

\section{2- REVISÃO DE LITERATURA}

\section{1- RECONHECIMENTO DE VOZ}

A voz humana é a forma mais simples, natural e eficaz do ser humano expressar seus pensamentosetransmitirinformaçõess. Nestecontexto,acapacidadedepercepçãoecompreensão da referida voz por equipamentos visando facilitar e agilizar a comunicação homem-máquina, 
tem sido amplamente desenvolvida nas últimasdécadas.

O funcionamento do reconhecimento de voz pode ser resumido basicamente como: a voz humana é percebida como variações da pressão sonora, e deve ser convertida em sinal elétricopor meio de um transdutor eletroacústico, como o microfone. Após passar por um circuito condicionador, que garante nível e cortes de frequências adequados, o sinal é convertido de analógico para digital por um conversor A/D (CARDOSO, SERGIO A., 2010).

\subsection{1- MÉTODOS DE RECONHECIMENTO}

O reconhecimento da fala é subdividido no Reconhecimento Automático do Locutor (RAL) e no Reconhecimento Automático da Voz (RAV), sendo que aquele busca diferenciar os indivíduos tanto pela identificação como pela verificação de locuções, por meio da extração de características distintas que cada indivíduo apresenta (VALIATI, Joao Francisco, 2000), enquanto este, por sua vez, deve compreender automaticamente uma elocução, que pode ser tratada sob 3 aspectos: o reconhecimento de palavras isoladas, palavras conectadas e fala contínua.

Deve ser ressaltado que uma das aplicações do RAV condiciona-se à dependência ou não do locutorno reconhecimento, sendo que sistemasdependentesdolocutorsãocapazesdereconhecerafaladeumúnico locutoraoqualfoitreinado. Esteseráosistemadereconhecimentoautomáticodevozutilizado neste trabalho e os usuários deste tipo de sistema devem sempre treiná-lo antes de utilizá-lo. O treinamento envolve alguns fatores relativos, quais sejam: a escolha de umvocabulário; cada sistema é treinado a fim de reconhecer a fala de um determinado locutor e seu vocabulárioespecífico; a necessidade que cada usuário repita o vocabulário de palavras ordenadas diversas vezespara ser criado umpadrão e por fim, o sistema deve ser treinado em um ambienteapropriado.

Sendo assim, após a conclusão da fase de treinamento pelo usuário, este será habilitado pelosistemaaoseuvocabulário específico.

Segundo os autores Valiati e João Francisco (2000), o citado sistema possui algumas vantagens e desvantagens. Entre as vantagens, destacam-se: A flexibilidade do vocabulário (o usuário é capaz de adicionar ou alterar palavras para um vocabulário simples, bastando-lhe um treinamentoprévio); o tamanho do vocabulário (o sistema pode suportar um vocabulário extenso). Por outro lado, as desvantagens observadas em sistemas deste tiposão: a limitação do número de usuários; a necessidade de uma grande quantidade de processamento antes que o 
sistema venha a ser utilizado e o fato de certas aplicações poderem englobar muitos usuários, pode ocasionar uma elevada capacidade de armazenamento do sistema para os parâmetros dos diversoslocutores; a fase de treinamento é desagradável aousuário e devidoafatorescomo,cansaço,doença,posiçãoetipodomicrofone,avozdomesmolocutor poderá variar.

\section{APLICAÇÕES DO RECONHECIMENTO DEVOZ}

\section{INTERFACES EM SISTEMAS DECOMPUTAÇÃO}

As aplicações deste tipo utilizam o reconhecimento de fala como uma interface para sistemas decomputador,assimcomoparaaplicativosqueexecutamsobreessessistemas.Amaiorparte destes, utilizam a fala para a manipulação de menus, janelas, caixas de diálogo,palhetas e outroscomponentes.

\section{AUXÍLIO ADEFICIENTES}

Os deficientes, em sua grande maioria, com impedimento motor ou visual,usamoreconhecimentodefalapararealizaremtarefasqueostornem mais independentes em sua vida pessoal, sendo o surgimento de tal reconhecimento, principalmente direcionado ao auxílio das pessoas com deficiências físicas.

\section{CONTROLE DEAMBIENTES}

Ocontroledecadeirasderoda,camasdehospital,luzesedemaisitensdoambientepessoalsão úteis para auxiliar em tarefas desta natureza por meio da voz, tornando o ambiente adequado às necessidades de cadausuário.

Além dessas três principais aplicações, o comando de voz está amplamente difundido no cotidiano, estando presente em smartphones, podendo citar, a título de exemplificação, 
oGoogle assistente, a Siri, casas com expoentes como o google home e Alexa, bem como vários eletrodomésticos e carros fabricados com comando acionado por voz.

\section{3 -METODOLOGIA}

Para atingir a capacidade de interpretar comandos de voz, sendo capaz de obedecê-los e se mover de acordo, foi construído um robô, que consiste em um Arduino modelo UNO R3, módulo de reconhecimento de voz modelo V3.0, ponte H modelo L9110S, dois motores DC e fonte de tensãoindependente.

\section{-FERRAMENTAS}

Parao

presentetrabalhofoiescolhidodesenvolverumrobôdeplataformaretangularsobretrêsrodas, sendoduasdelasmovidaspormotoreseaterceiradeapoio,conforme demonstrado pela figura3.1. A construção foi escolhida da forma exposta, visando facilitar a realização decurvas.

Figura 3.1- Aspectos estruturais

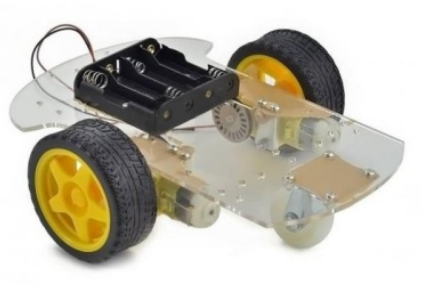

Fonte:filipeflop.com

Sendo assim, o sistema de controle está baseado no microcontrolador Arduino UNO $\mathrm{R} 3$, conforme demostrado na figura acima.

O Arduino é uma plataforma de código aberto baseada em hardware e software de usar. A plataforma é baseada na linguagem $\mathrm{C} / \mathrm{C}++$ e neste trabalho, sendo ele responsável por processar as informações enviadas pelo módulo de voz e aplicá-las no programa, controlando o movimento dorobô. 
Figura 3.2- Arduino UNO R3

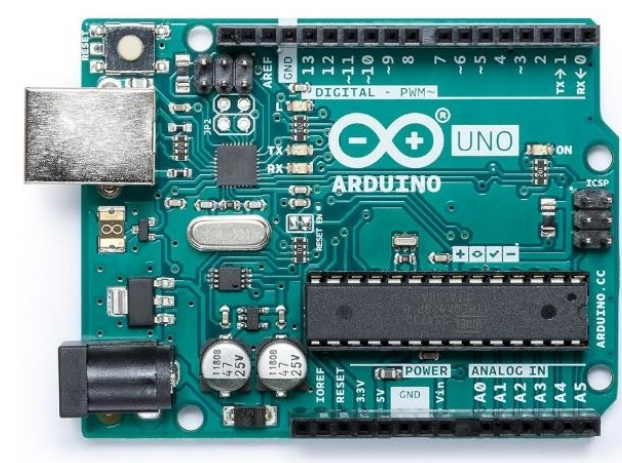

Fonte: Amazon.com

A interpretação dos comandos de voz fica sob a responsabilidade de outro hardware, o módulo de voz, Módulo de reconhecimento de Voz V3 da empresa ELECHOUSE, conforme retratado na imagem, tendo em vista que este aparelho ao interpretar os comandos, os transforma em dados que são enviados ao Arduinoe integrados noprograma.'

Figura 3.3- Módulo de reconhecimento de Voz V3

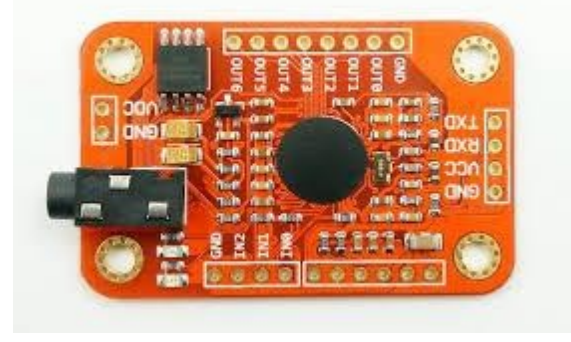

Fonte: elechouse.com

Para controlar a velocidade e o sentido de giro dos motores por PWM, do inglês Pulse Width Modulation eem português Modulação por Largura de Pulso (MLP), utilizou-se a ponte H modelo L9110S, como analisado na figura 3.4, a qual possui entrada para dois motores, que podem ser de até12Ve800mA.Odispositivo,alémdepossibilitarocontroledosmotores,permitequesejam controlados de formaindependente. 


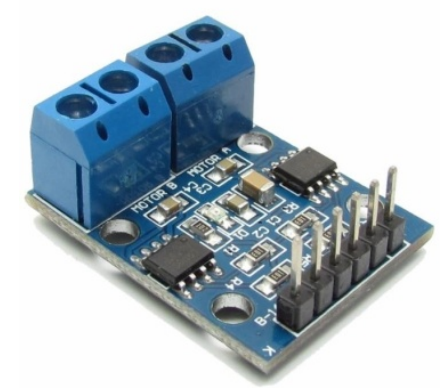

Fonte:multipecas.curitiba.br

Além das componentes citados anteriormente, também foram utilizados para realização deste trabalho outros equipamentos, sendo eles:2 Motores DC(3 6v), 1 Bateria 9v., 4 Pilhas alcalinas 1,5v., 1 Suporte para 4pilhas, 1 Clip para alimentar Arduino utilizando bateria 9v., 2 Rodas deborracha, 1 Roda boba(universal), 15 Jumpers, 1 Mini Protoboard 170pontos, 1 Jogo deparafusos.

\section{- MÉTODO DE DESENVOLVIMENTO DAPROGRAMAÇÃO}

O objeto a ser trabalhado será capaz de obedecer inicialmente a quatro comandos de voz, os quais dois são para distância de locomoção e dois de mudança de trajetória. Os comandos de locomoção serão os de se mover em distâncias de 1 metro e para se locomover em uma trajetória determinada.

Diante disso, pondera-se que a mudança de trajetória será estabelecida com os comandos de virar à esquerda e virar à direita e para realização deste trabalho, é necessário um algoritmo capaz de alcançar o objetivo estabelecido.

Com o objetivo de alcançar o programa final, o desenvolvimento do programa foi dividido em 3 etapas. Cada etapa focará em uma parte importante visando entendimento dos componentes utilizados, sendo a 1 delas, a que consiste em utilizar no lugar dos motores dois LEDs, que devem ser acionados por 4 botões, que simulam os comandos de voz. O botão 1 aciona os dois LEDs por 1 segundo, o botão 2 aciona somente o LED 1 por 1 segundo e o botão 3 faz o mesmo com o LED 2, o botão 4 aciona os dois LEDs por 1 segundo, posteriormente aciona somente o LED 1 por 1 segundo e volta a acionar os dois LEDs por 1 segundo.

\section{Programaetapa 1:}




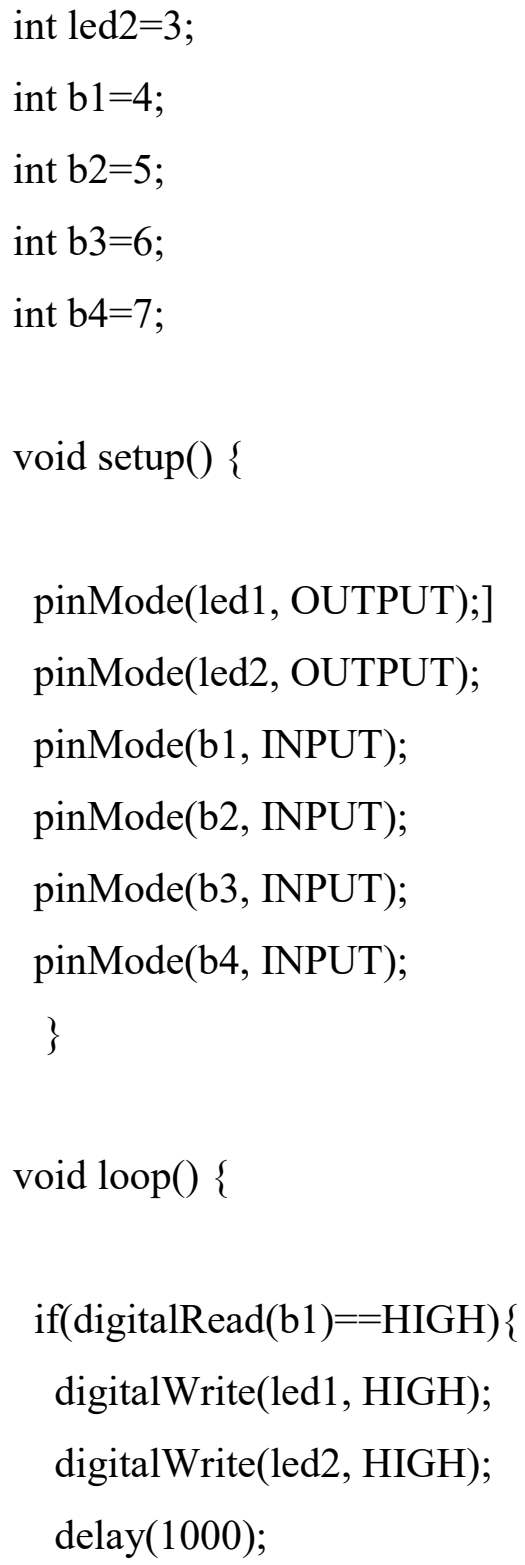

\section{4 - RESULTADOS EDISCUSSÕES}

Como apresentado na revisão literária, o módulo de reconhecimento de voz (V3) usado, utiliza uma das aplicações do RAV, no qual condiciona-se à dependência do locutor no reconhecimento. Dito isso, foi escolhido um vocabulário específico, em que foram escolhidas as palavras: deslocar, direita, esquerda e trajeto.

Sendo assim, como o reconhecimento ficou limitado a um único locutor, este foi responsável pelo treinamento do módulo no reconhecimento, sendo dito várias vezes as palavras usadas.

\section{-PROTÓTIPO}

Com o módulo reconhecimento de voz devidamente preparado, assim como todo o 
programa, foi construído, em seguida, um protótipo, conforme se observa na figura 4.1. Com ele, foi obtido o tempo necessário para os deslocamentos escolhidos.

Figura 4.1 - Protótipo

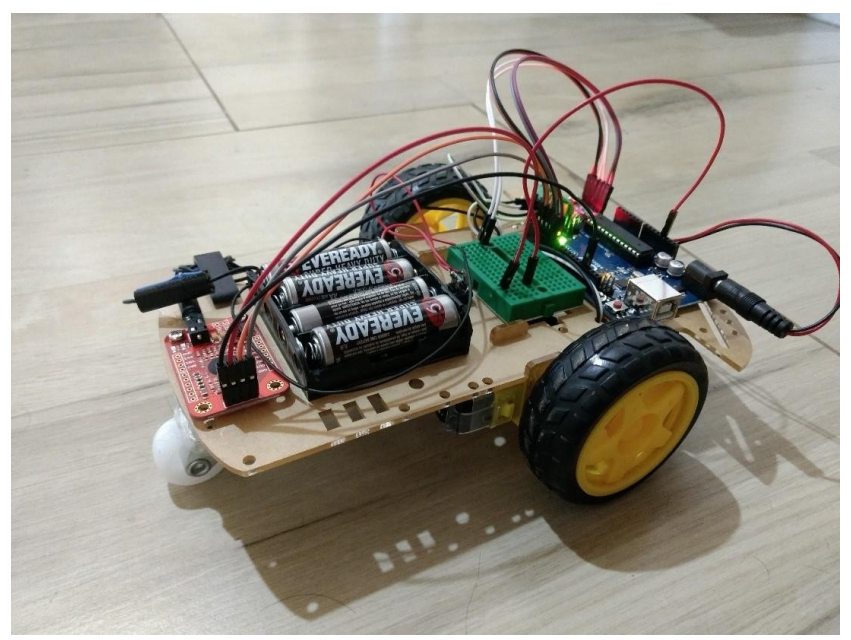

Figura 4.3 -Protótipo

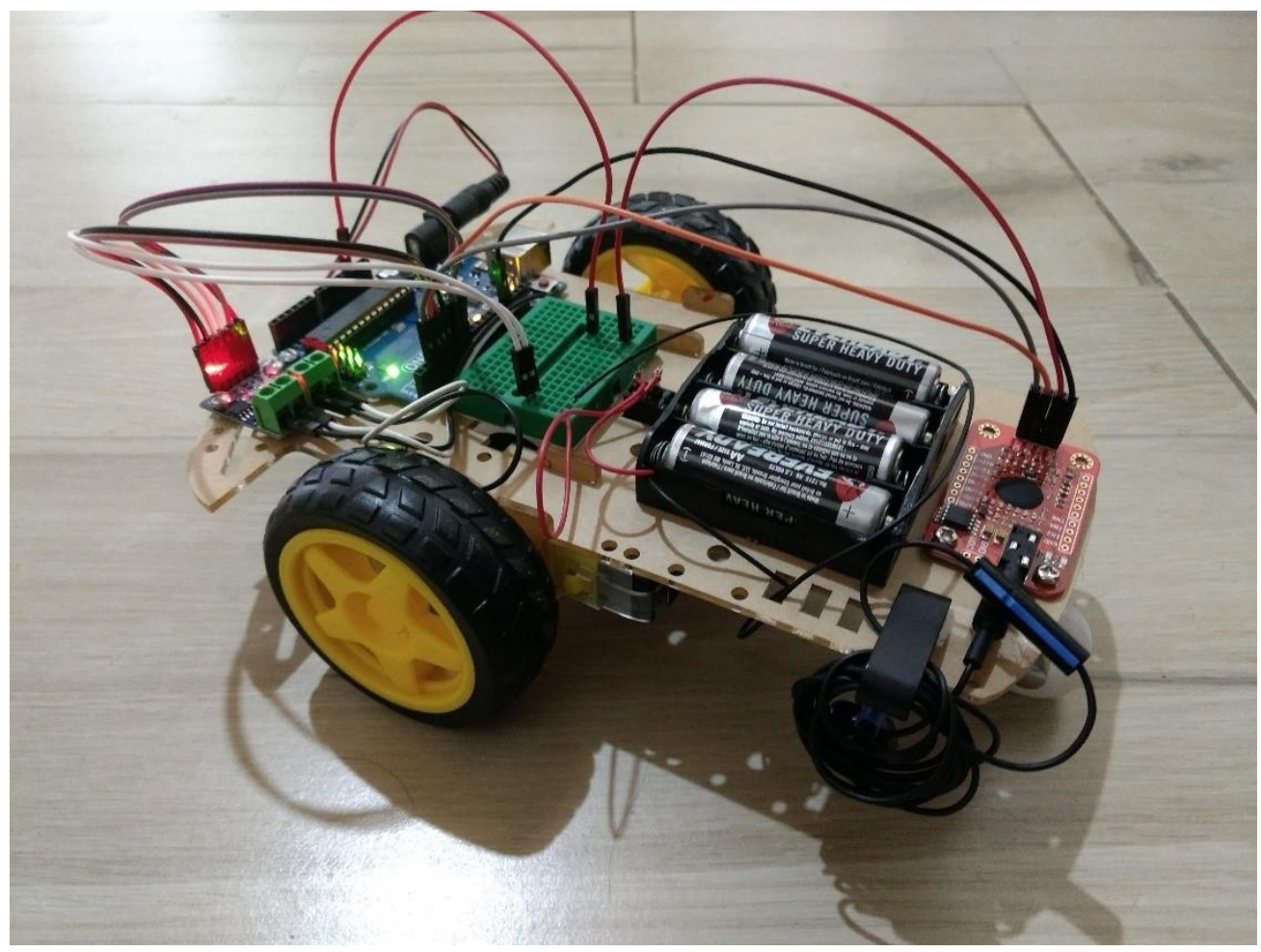

Para determinar o tempo necessário para alcançar 1 metro, foi demarcado no solo, bem como cronometrado tempo que o objeto leva para alcançar 1 metro, como demonstrado nas figuras abaixo. 


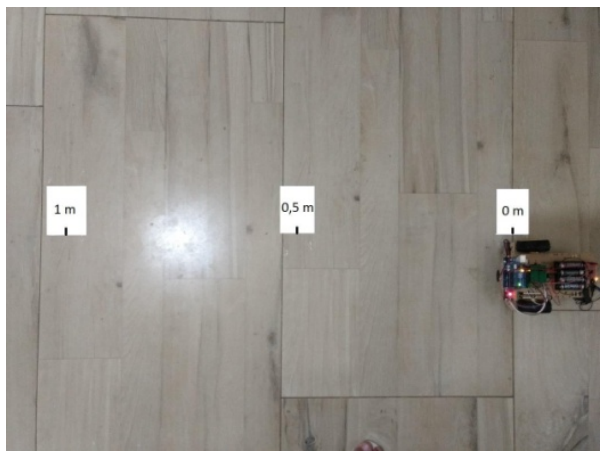

Figura 4.4 - cálculo do tempo dedeslocamento

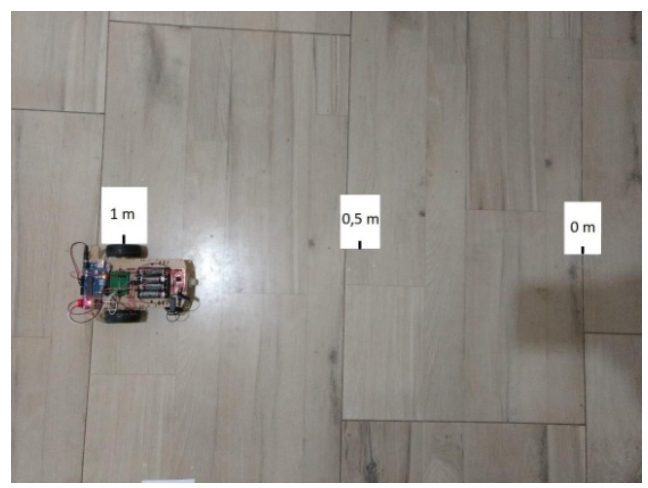

Figura 4.5 - cálculo do tempo dedeslocamento

Logo,

paradeterminarotemponecessárioparavirar90graus,foidemarcadonosoloemarcadotempo que o objeto leva para virar, como pode-se analisar nas figurasabaixo.

Figura 4.6 - cálculo do tempo derotação

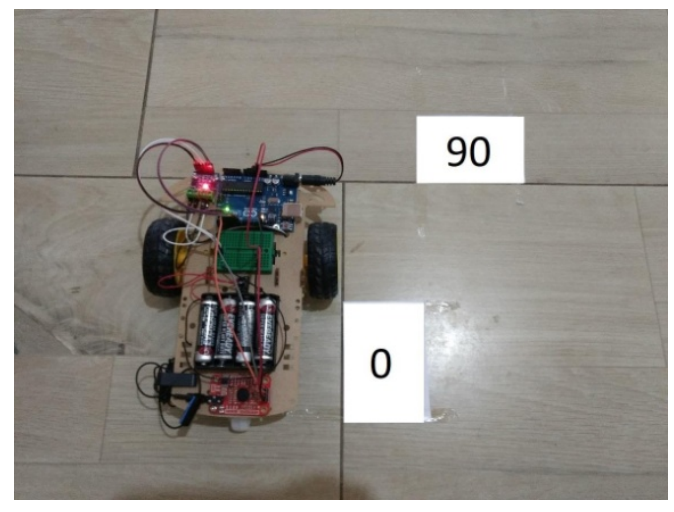

Figura 4.7 - cálculo do tempo derotação

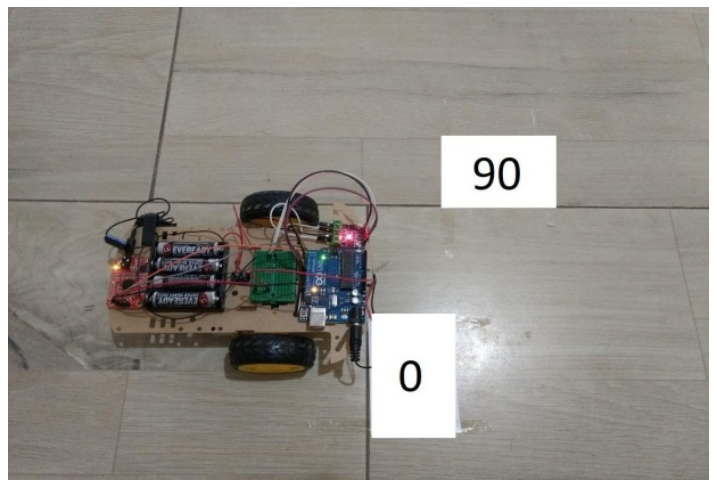




\section{- DIFICULDADES NODESENVOLVIMENTO}

Para o desenvolvimento do protótipo, as principais dificuldades foram apresentadas no reconhecimento de voz, tendo em vista que sua precisão está diretamente ligada ao microfone utilizado, ao tomde voz do locutor e ao nível de ruído ao qual o objeto está inserido. Estes três fatores oscilam constantemente, fato este, que dificultou consideravelmente o projeto, o que teve como influência direta no trabalhorealizado. Istopoderáseramenizadoemtrabalhosfuturoscomautilizaçãodemétodos de reconhecimento de voz melhor elaborados, como por exemplo, os desenvolvidos pelo Google, que são aplicados principalmente emsmartphones.

Verificou-se ainda, a existência de um outro problema, sendo este, no tempo de deslocamento, uma vez que há o oscilamento de acordo com o nível de carga das pilhas utilizadas e com o tipo de solo no qual o objeto está inserido.

\section{5 -CONCLUSÃO}

Como demonstrado, o reconhecimento de voz é amplamente explorado pela tecnologia e sua aplicação na robótica é formidável, principalmente em robôs autônomos móveis. Com isso, o aprendizado adquirido no desenvolvimento de projetos iniciais, como este, é necessário para o desenvolvimento de projetos futuros com uma aplicação mais complexa, como por exemplo, o auxílio em tarefas ariscadas e em caso de impossibilidade de locomoção.

Pode-se ponderar então, que o presente trabalho trata-se de um ótimo ponto de partida para o desenvolvimento destes projetos.

Neste trabalho, todos os objetivos apresentados foram alcançados e pôde ser concluído que o sistema desenvolvido tem a capacidade de interpretar comandos de voz, sendo capaz de se mover de uma posição conhecida a uma nova localização determinada pelo comando.

\section{REFERÊNCIAS BIBLIOGRÁFICAS}

CARDOSO,SERGIOA.etal.Sesame:sistemadereconhecimentodecomandosdevozutilizandopds e rna. In: Anais do XVIII Congresso Brasileiro de Automática. 2010. p.1316-1323.

VALIATI, Joao Francisco. Reconhecimento de voz para comandos de direcionamento por meio de redes neurais. 2000.

JÁCOBO, Justo Emilio Alvarez. Desenvolvimento de um Robô Autônomo Móvel Versátil utilizando Arquitetura Subsumption. Faculdade de Engenharia Mecânica, Universidade Estadual de Campinas, 2001.

ROMANO, V.; DUTRA, M. Introdução a robótica industrial. Robótica Industrial: Aplicação na Indústria de Manufatura e de Processo, São Paulo: Edgard Blücher, p. 1-19, 2002. 